\title{
Allometric modelling of crown width for white spruce by fixed- and mixed-effects models
}

\author{
by Yuqing Yang ${ }^{1 *}$ and Shongming Huang ${ }^{1}$
}

\begin{abstract}
Crown width is an important predictor for tree growth, crown surface area, forest canopy cover, tree-crown profiles and wildlife habitat indices. This paper developed crown width models for white spruce (Picea glauca (Moench) Voss) in Alberta using allometric fixed and mixed models with varying degrees of model complexity. Diameter at breast height was the most important predictor and was used in the base model. Crown ratio, height-diameter ratio and two competition indices (CIs) were additional predictors added to the base model to form four expanded models. At each level of complexity, a fixed model and a mixed model were fitted. Improved fits were achieved for both model types as model complexity increased, and all mixed models provided much better fits than their fixed model counterparts. Population-averaged (PA) predictions by fixed models, and typical mean (TM), PA and plot-specific (PS) predictions by mixed models were compared on both model fitting and validation data. TM and PA predictions by each mixed model were almost identical, and they were less accurate than PA predictions by the fixed model counterpart, especially for simpler models. Much better PS predictions by mixed models were observed on both datasets. Although the distancedependent CI was slightly better than the distance-independent CI, both were not recommended due to their marginal contributions to crown width predictions.
\end{abstract}

Keywords: crown width, mixed model, competition index, model prediction, white spruce

\section{RÉSUMÉ}

La largeur de cime est une variable importante pour estimer la croissance, la surface de cime, le couvert forestier, le profil de cime et les indices d'habitat pour la faune. Cet article propose un modèle de largeur de cime élaboré pour lépinette blanche (Picea glauca (Moench) Voss) de l'Alberta à l'aide de modèles allométriques fixes et mixtes de divers niveaux de complexité. Le diamètre à hauteur de poitrine s'est avéré être la variable la plus importante et celle qui a été retenue dans le modèle de base. Le coefficient de forme, le rapport hauteur-diamètre et deux indices de compétition (CIs) ont été ajoutés au modèle de base afin de créer quatre modèles élargis. On a ajusté un modèle fixe et un modèle mixte pour chaque niveau de complexité. Dans les deux cas, l’ajustement du modèle s’améliorait à mesure qu’augmentait sa complexité, et les modèles mixtes donnaient un meilleur ajustement que les modèles fixes. On a comparé les prévisions moyennes avec celles au niveau des populations (Population-averaged -PA) obtenues avec les modèles fixes et les moyennes-types (TM), les prévisions PA et celles par placette (PS) obtenues avec les modèles mixtes à la fois sur leur ajustement et avec des ensembles de données de validation. Les prévisions TM et PA pour chacun des modèles mixtes ont été identiques et se sont avérées moins précises que les prévisions PA à l'aide des modèles fixes, surtout avec les modèles les plus simples. On a toutefois obtenu de bien meilleures prévisions PS avec les modèles mixtes lors de la validation avec les deux jeux de données. Bien que les $\mathrm{CI}$ en fonction de la distance donnent des résultats légèrement meilleurs que les $\mathrm{CI}$ hors-distance, aucun naa été retenu en raison de leur apport limité à la prévision de la largeur de cime.

Mots-clés : largeur de cime, modèle mixte, indice de compétition, prévision à l'aide d’un modèle, épinette blanche

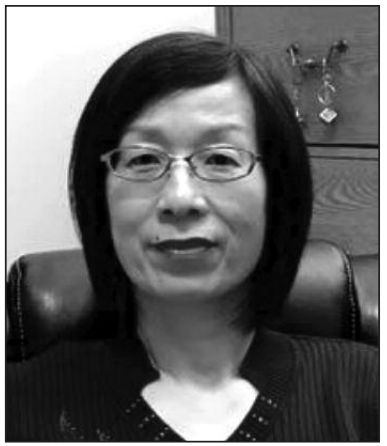

Yuqing Yang

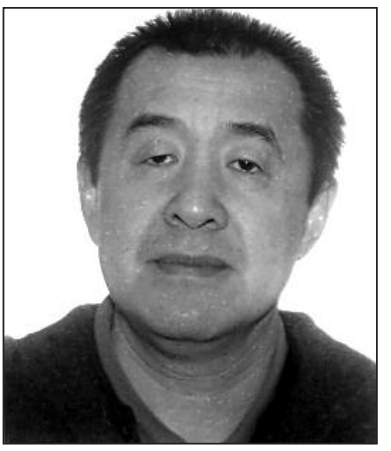

Shongming Huang

\section{Introduction}

Morphology of tree crowns reflects the cumulative competition effects over time and is central to many aspects of forest ecology and dynamics. Tree crown size is closely related to the photosynthetic capacity of a tree (Hemery et al. 2005) and often reflects the allocated space as determined by the sizes and locations of its neighbours in a stand (Rouvinen and Kuuluvainen 1997). Large and dense crowns are often associated with higher growth rates, while small and sparse crowns can be a result of unfavorable site conditions related to competition, drought and diseases (Jiménez-Pérez et al. 2006). Crown width, one of the primary crown size measures, is important for several key factors in stand management. At the

\footnotetext{
${ }^{1}$ Forest Management Branch, Alberta Agriculture and Forestry, $8^{\text {th }}$ Floor, 9920-108 Street, Edmonton, AB T5K 2M4

*Corresponding author: yuqing.yang@gov.ab.ca
} 
tree level, crown width indicates the level of competition among trees. Further, crowns contribute to stand-level measures of crown closure (aka canopy cover percent) that are often used to indicate stand-level competition and are key indicators of habitat quality. As a result, crown width has been used to indicate growth efficiency and tree- and stand-level competition and as an important predictor variable for tree and stand attributes such as tree growth and volume (Condés and Sterba 2005), crown surface area and volume (Zarnoch et al. 2004), forest canopy cover (Gill et al. 2000), tree-crown profiles (Crecente-Campo et al. 2009) and wildlife habitat indices (Hays et al. 1981).

Tree crown width can be represented as: 1) the estimated maximum crown width-based models using trees under very low competition, i.e., open-grown trees (Russell and Weiskittel 2011); 2) the largest crown width over the tree profile (Hann 1998, Russell and Weiskittel 2011); or 3) complete crown profiles of crown widths over vertical points on the tree bole (Hann 1998, Crecente-Campo et al. 2009). Maximum crown widths are mainly used for computing crown competition factors. Largest crown widths have been used as a measure for competition for light in several competition index (CI) measures in individual tree growth models (Biging and Dobbertin 1995). Crown profiles may be used to get inter-tree competition and tree vigour measures and to model windthrow, snow damage risk, fire behavior and crown fire risk (Crecente-Campo et al. 2009). For example, in the Forest Vegetation Simulator, maximum crown widths were calculated for all trees in a plot and were used to calculate crown competition factors. For forest inventories, often the largest crown widths of all trees are summed to obtain canopy cover percentages (Crookston and Dixon 2005). Hann (1998) used all three measures of crown widths for calculating crown closure, which was used for predicting individual tree height growth and mortality in the ORGANON model. Crown width measurements can be difficult and time-consuming to measure in the field on every tree. As a result, they are not typically measured in forest inventories; when they are measured, this is often for a subsample of trees in plots. Crown width models may be used to impute the missing crown width measures since they are often a function of commonly measured stand and tree attributes.

Diameter at breast height (DBH; $1.3 \mathrm{~m}$ above the ground) is well-correlated with crown width for many species and stand types and is often used as an essential and effective predictor for crown width. In their study, Russell and Weiskittell (2011) determined that model forms were critical for accurate and robust crown width predictions. Simple linear models between crown width and DBH are often adequate. However, more complex models better reflect the complex relationships between crown width and stand and tree attributes and are better for estimating crown widths (Gill et al. 2000, Thorpe et al. 2010, Fu et al. 2013).

In addition to stem diameter, other variables have been used to improve crown width predictions, including tree-level variables such as height and crown length, stand-level variables such as stand density and basal area, and competition related variables expressed by various CIs (Rouvinen and Kuuluvainen 1997, Gill et al. 2000, Bragg 2001, Ledermann and Stage 2001, Thorpe et al. 2010). Crown widths are often over-predicted in dense stands and under-predicted in sparse stands when crown width is modelled by tree size alone, and competition effects need to be considered for comprehensive crown models (Thorpe et al. 2010).

Mixed-effects models, referred to as mixed models in this paper, have been increasingly applied in growth and yield modelling in recent years. Mixed models are suitable for analyzing longitudinal data due to their flexibility in dealing with different data structures such as irregular and/or unbalanced data. They are able to handle the lack of independence caused by grouped data structures associated with clustered or repeatedly measured data (Pinheiro and Bates 2004, Temesgen et al. 2008, Yang and Huang 2011, Meng et al. 2012). This is important in situations where statistical inferences are essential, especially for forest growth and yield models mostly developed from limited sampling data. In addition, mixed models can provide better local predictions. Consisting of fixed and random parameters, mixed models account for covariate or treatment effects through fixed parameters as in ordinary least squares. Various sources of heterogeneity and randomness in the data caused by known and unknown factors can be accounted for by random parameters. Residual variances and within-subject correlation can be modelled directly by a variance function and a covariance structure (Vonesh and Chinchilli 1997).

Because of their many advantages, mixed models have been used widely for modeling various stand and tree characteristics. However, Kershaw et al. (2009) argued that many mixed models were developed based on "naïve" fixed models and relatively simple model forms with a limited number of predictors. Through an example of modelling maximum knot size, they demonstrated that all mixed models were significantly better than their fixed model counterparts. However, the amounts of improvement of the mixed models over the corresponding fixed models decreased as model complexity increased, indicating that more complex fixed models should be considered when developing mixed models. This is not surprising since all models have a prediction component and an error component. If more data variation is explained by the prediction component, unaccounted for variation will drop. Therefore, when the fixed-effects part becomes more complex, the random-effects part, including the error term, can be simplified. On the other hand, the requirement for model complexity depends on the intended use of the model, and measurement cost should always be kept in mind when developing a predictive model.

The overall objective of this study was to develop a crown width model for white spruce (Picea glauca (Moench) Voss) in Alberta. The specific objectives were: (1) to select a base model of crown width as a function of $\mathrm{DBH}$; (2) to examine other tree characteristics and various CIs for their potential in improving crown width model fits and predictions; (3) to develop fixed and mixed models of varying degrees of complexity; and, (4) to compare the fitted models for their abilities in making crown width predictions on model fitting and model validation data.

\section{Materials and Methods \\ Data description}

The data used for this study were a part of the provincial permanent sample plot (PSP) program collected and managed by the Alberta government. The PSP program was initiated in 
the 1960s, and the plots were distributed across the entire province and covered a wide range of stand and site conditions, including stands with various species mixtures. Different plot sizes were used, from 200 $\mathrm{m}^{2}$ to $2000 \mathrm{~m}^{2}$ with most plots being $1000 \mathrm{~m}^{2}$. A nested plot design was used to measure trees of different sizes, with larger trees $(\mathrm{DBH} \geq 9.1 \mathrm{~cm})$ stem mapped and measured in main plots and smaller trees measured in subplots. A detailed description of the data collection procedure is provided in ASRD (2005). Since crown width measurements were first collected in 2000 on a sample of trees in each plot, only data measured in and after 2000 were used for this study. For each measured tree, four crown radius measurements were taken at four cardinal directions, and crown width was calculated as two times the arithmetic mean of the four crown radius measurements. The dataset was randomly split into a fitting and a validation dataset using plot as the basic unit. In total, there were 1956 white spruce trees from 319 plots in the fitting dataset and 1648 from 246 plots in the validation dataset. Temporal correlation was not an issue since all trees were measured once for crown width, except for 46 trees from three plots in the validation dataset with two measurements.

\section{Model development}

\section{Base model selection}

Because the main purpose of this study was to develop a crown width prediction model, the fixed-effects modelling approach was used to guide model selection. As stated earlier, crown width is correlated with tree size and stand characteristics, but $\mathrm{DBH}$ is, by far, the most common predictor of crown width (Bechtold 2003). For this study, a base model of crown width $(\mathrm{CW}, \mathrm{m})$ as a function of tree $\mathrm{DBH}(\mathrm{cm})$ was selected first based on ordinary least squares fits using fixedeffects only. Various model forms commonly used for tree allometric models were considered; four models were selected as alternative base models after preliminary analyses:

$$
\begin{array}{ll}
\text { (1) } & \mathrm{CW}=\beta_{0}+\beta_{1} \mathrm{DBH}+\varepsilon \\
\text { (2) } & \mathrm{CW}=\beta_{0} \mathrm{DBH}^{\beta_{1}}+\varepsilon \\
\text { (3) } & \mathrm{CW}=\beta_{0} \exp \left(\beta_{1} \mathrm{DBH}\right)+\varepsilon \\
\text { (4) } & \mathrm{CW}=\beta_{0}\left[1-\exp \left(-\beta_{1} \mathrm{DBH}^{2}\right)\right]+\varepsilon
\end{array}
$$

Where $\beta_{0}$ and $\beta_{1}$ are parameters to be estimated, $\varepsilon$ the error, model 1 is linear and models $2-4$ are nonlinear. PROC MODEL in SAS (version 9.3) was used for parameter estimation, and the final base model was selected based on two fit statistics: the coefficient of determination $\left(\mathrm{R}^{2}\right)$ and the root mean square error (RMSE). Residuals were also plotted against the observed DBHs and predicted CWs to examine any potential trend.

\section{Expanded models}

Although DBH is the most common predictor of crown width, other predictors have been shown to improve crown width models. Some predictors were tree dimension variables such as tree height and crown length (Hann 1998) or variables calculated from tree dimensions such as crown ratio (Sánchez-González et al. 2007) and height-diameter ratio (Hann 1998), while others were competition measures such as distance-dependent and distance-independent CIs (e.g., Bragg 2001, Paulo et al. 2002). Both tree dimension variables and various CIs were examined for their roles in improving crown width models.

Tree dimension variables examined in this study included tree height (HT), height to live crown (HTLC) and crown length (CL). Two predictors derived from tree dimension variables, crown ratio (CR, the ratio of crown length to tree height) and height-diameter ratio (HDR, the ratio of tree height to tree diameter), were also examined. Compared to crown width, height to live crown is easier to measure in the field, and is now measured for all trees in the provincial PSPs when tree heights are measured.

In addition, various CIs were examined as potential predictors (Table 1). The calculations for most of the CIs were straightforward. Stand density index was defined as the equivalent stand density (stems/ha) at a QMD of $25 \mathrm{~cm}$, i.e., SDI $=$ DEN $\times(25 / Q M D)^{-1.605}$ (Pretzsch and Deiler 2012). The five distance-dependent CIs are based on diameters of and distances between the subject tree and its competitors. They are relatively simple to calculate, but have similar predictive abilities to more complicated CIs for growth predic- 
Table 2. Summary statistics of the mean, minimum and maximum values for crown width (CW) and potential predictors in model fitting (1956 trees from 319 plots) and validation data (1648 trees from 246 plots)

\begin{tabular}{|c|c|c|c|c|c|c|}
\hline \multirow[b]{2}{*}{ Variable } & \multicolumn{3}{|c|}{ Model fitting data } & \multicolumn{3}{|c|}{ Model validation data } \\
\hline & Mean & Minimum & Maximum & Mean & Minimum & Maximum \\
\hline $\mathrm{CW}(\mathrm{m})$ & 3.36 & 0.45 & 10.35 & 2.96 & 0.65 & 8.40 \\
\hline \multicolumn{7}{|c|}{ Tree dimension based predictors } \\
\hline $\mathrm{DBH}(\mathrm{cm})$ & 21.78 & 9.10 & 78.20 & 24.30 & 9.10 & 69.60 \\
\hline $\mathrm{HT}(\mathrm{m})$ & 16.49 & 5.00 & 39.10 & 21.01 & 5.30 & 37.80 \\
\hline $\operatorname{HTLC}(\mathrm{m})$ & 6.40 & 0.10 & 25.80 & 10.02 & 0.20 & 26.80 \\
\hline $\mathrm{CL}(\mathrm{m})$ & 10.09 & 1.20 & 33.20 & 10.98 & 1.70 & 28.70 \\
\hline $\mathrm{CR}$ & 0.64 & 0.10 & 0.99 & 0.55 & 0.10 & 0.97 \\
\hline HDR & 0.80 & 0.36 & 1.66 & 0.90 & 0.30 & 1.57 \\
\hline \multicolumn{7}{|c|}{ Distance-independent CIs } \\
\hline $\mathrm{DEN}$ & 746.49 & 123.58 & 2324 & 778.48 & 212.56 & 2500 \\
\hline DEN_CON & 627.27 & 4.94 & 2299 & 537.37 & 10 & 2300 \\
\hline DEN_DEC & 119.22 & 0 & 1077 & 241.11 & 0 & 2070 \\
\hline $\mathrm{BA}$ & 34.63 & 7.77 & 70.24 & 35.53 & 14.62 & 55.76 \\
\hline BA_CON & 26.75 & 0.07 & 56.64 & 26.13 & 0.13 & 53.74 \\
\hline BA_DEC & 7.88 & 0 & 49.29 & 9.40 & 0 & 41.65 \\
\hline $\mathrm{QMD}$ & 25.60 & 14.80 & 44.56 & 25.69 & 12.69 & 38.94 \\
\hline QMD_CON & 24.55 & 9.20 & 43.81 & 25.05 & 10.48 & 44.82 \\
\hline QMD_DEC & 20.60 & 0 & 53.49 & 23.94 & 0 & 57.26 \\
\hline SDI & 706.24 & 156.28 & 1381.00 & 721.10 & 285.14 & 1245.95 \\
\hline SDI_CON & 555.32 & 1.99 & 1300.41 & 526.66 & 3.54 & 1245.95 \\
\hline SDI_DEC & 148.79 & 0 & 892.66 & 192.39 & 0 & 888.23 \\
\hline $\mathrm{BAL}$ & 26.02 & 0 & 64.09 & 24.19 & 0 & 54.86 \\
\hline BAL_CON & 19.60 & 0 & 55.89 & 17.09 & 0 & 50.71 \\
\hline BAL_DEC & 6.42 & 0 & 49.29 & 7.10 & 0 & 41.25 \\
\hline SDIL & 499.46 & 0 & 1309.28 & 463.52 & 0 & 1022.17 \\
\hline SDIL_CON & 383.36 & 0 & 1282.23 & 323.54 & 0 & 991.52 \\
\hline SDIL_DEC & 115.18 & 0 & 892.66 & 139.32 & 0 & 874.79 \\
\hline \multicolumn{7}{|c|}{ Distance-dependent CIs } \\
\hline CI1 & 5.03 & 0 & 23.71 & 4.74 & 0 & 20.92 \\
\hline CI1_CON & 4.13 & 0 & 23.71 & 3.20 & 0 & 18.30 \\
\hline CI1_DEC & 0.90 & 0 & 16.48 & 1.55 & 0 & 20.92 \\
\hline $\mathrm{CI} 2$ & 43.28 & 0 & 198.86 & 40.52 & 0 & 164.20 \\
\hline CI2_CON & 35.50 & 0 & 198.86 & 27.23 & 0 & 150.04 \\
\hline CI2_DEC & 7.78 & 0 & 131.52 & 13.28 & 0 & 164.20 \\
\hline $\mathrm{CI} 3$ & 112.94 & 0 & 527.16 & 120.53 & 0 & 927.49 \\
\hline CI3_CON & 91.81 & 0 & 509.10 & 86.73 & 0 & 927.49 \\
\hline CI3_DEC & 21.13 & 0 & 510.28 & 33.80 & 0 & 766.73 \\
\hline $\mathrm{CI} 4$ & 4.13 & 0 & 336.23 & 4.71 & 0 & 494.16 \\
\hline CI4_CON & 3.22 & 0 & 234.29 & 2.98 & 0 & 394.85 \\
\hline CI4_DEC & 0.90 & 0 & 333.63 & 1.73 & 0 & 494.16 \\
\hline CI5 & 12.01 & 0 & 137.22 & 9.57 & 0 & 161.87 \\
\hline CI5_CON & 9.33 & 0 & 88.96 & 6.32 & 0 & 150.45 \\
\hline CI5_DEC & 2.69 & 0 & 112.47 & 3.24 & 0 & 123.44 \\
\hline
\end{tabular}

HT is tree height, HTLC is height to live crown, CL is crown length, CR is crown ratio, HDR is height-diameter ratio, and all CIs are defined in Table 1. Three values are provided for each CI: CI for all species combined (CI), CI for coniferous group (CI_CON), and CI for deciduous group (CI_DEC).

tions (Lorimer 1983). A 10-m radius was used for defining competitors for each target tree, and an area weighting method (Das et al. 2008) was used to correct for edge effects. For each CI, three values were calculated: CI for all species combined, CI for coniferous species and CI for deciduous species. Table 2 provides a summary of crown width and all potential predictors examined in this study for the two datasets. These potential predictors were used to develop different levels of expanded models.
First, only tree dimension-based variables were examined for inclusion into the base model. Next, various CIs were examined, and one distance-dependent $\mathrm{CI}$ and one distanceindependent $\mathrm{CI}$ were selected and subsequently compared for their abilities in improving crown width models. The objective was to assess if the more complex distance-dependent CIs were superior to the simpler distance-independent CIs for crown width modelling and prediction. As a result of these modelling efforts, five crown width models with increasing 
numbers of predictors were fitted: (1) a base model, (2) a level 1 expanded model by incorporating one tree dimensionbased predictor into the base model, (3) a level 2 expanded model by incorporating another tree dimension-based predictor into the level 1 model, and (4) two level 3 expanded models, one with a distance-dependent CI incorporated into the level 2 model and another with a distance-independent CI incorporated into the level 2 model. For each level of expanded model, eligible variables were added to the lower level model one at a time, and the one with the highest $\mathrm{R}^{2}$ and lowest RMSE was selected. For the selected models, Akaike's information criterion (AIC) and Schwarz's Bayesian information criterion (BIC) were also provided.

\section{Mixed models}

Based on the five fixed models, nonlinear mixed models were subsequently fitted by adding random parameters to the fixed parameters. A nonlinear mixed crown width model can be expressed as:

$$
\mathrm{CW}_{i}=f\left(\mathrm{x}_{i}, \beta, \mathrm{u}_{i}\right)+\varepsilon_{i}
$$

Where $\mathbf{C W}_{i}$ is a vector of tree crown widths for plot $i=1,2$, $\ldots, m, m$ is the number of plots; $f(\cdot)$ is a nonlinear function of the covariate matrix $\mathbf{x}_{i}$, a fixed parameter vector $\boldsymbol{\beta}$ common to all plots and a random parameter vector $\mathrm{u}_{i}$ unique for each plot; and $\boldsymbol{\varepsilon}_{i}$ is a matrix of unknown within-plot errors. The $\mathbf{u}_{i}$ and $\boldsymbol{\varepsilon}_{i}$ are often assumed to be uncorrelated and normally distributed with mean zero and variance-covariance matrices $\mathbf{D}$ and $\mathbf{R}_{i}$, respectively, i.e., $\mathbf{u}_{i} \sim N(\mathbf{0}, \mathbf{D})$ and $\boldsymbol{\varepsilon}_{i} \sim N\left(\mathbf{0}, \mathbf{R}_{\mathrm{i}}\right)$.

The ZERO expansion method under the SAS macro NLINMIX (Littell et al. 2006, SAS version 9.3) was used for parameter estimation. For each fixed model, all possible scenarios of random parameter inclusion were examined, and the best model was selected using the AIC and BIC statistics.

\section{Model application and evaluation}

The fitted fixed and mixed models were subsequently used for making different types of crown width predictions. Applications of the fixed models were straight-forward. Population-averaged (PA) predictions were produced for all trees in all plots. Applications of the mixed models, on the other hand, were more complicated. Three types of CW predictions were produced: (1) plot-specific (PS) predictions; (2) typical mean (TM) predictions; and (3) PA predictions to best mimic PA predictions by fixed models. These three types of CW predictions were produced as follows:

(1) To make PS predictions, plot-specific random parameters were predicted first by eq. 6. Measured CW and predictor data were needed for at least one tree in a plot. PS predictions for the remaining trees in the same plot were then calculated by eq. 7 (Vonesh and Chinchilli 1997):

(6) $\hat{\mathrm{u}}_{i}=\widehat{\mathrm{D}} \mathrm{Z}_{i}^{\prime}\left(\mathrm{Z}_{i} \widehat{\mathrm{D}} Z_{i}^{\prime}+\widehat{\mathrm{R}}_{i}\right)^{-1}\left[\mathrm{CW}_{i}-f\left(\mathrm{x}_{i}, \widehat{\beta}, 0\right)\right]$

(7) $\widehat{\mathrm{CW}}_{i}=f\left(\mathrm{x}_{i}, \widehat{\beta}, 0\right)+\mathrm{Z}_{i} \hat{\mathrm{u}}_{i}$

(2) To make TM predictions, only fixed parameters were used by setting the random effects to zero, a specific case of PS predictions (McCulloch and Searle 2001). However, it has been demonstrated that TM predictions do not fully represent the mean response of a population for nonlinear mixed models (Fitzmaurice et al. 2004, Meng et al. 2009, Burkhart and Tome 2012), especially when the amount of inter-plot variability is large (Davidian and Giltnan 2003). Predictions are typically biased, but biases could be small (Davidian and Giltnan 2003). Nevertheless, such predictions have been widely used in practice when prior information is not available at the plot level (Fang and Bailey 2001).

(3) PA predictions were produced by simulations to avoid potential biases in TM predictions (de-Miguel et al. 2012, Mehtätalo et al. 2015). For each mixed model, 10000 sets of random parameters were randomly generated based on the distribution of the random effects, i.e., $\mathbf{u}_{i} \sim N(\mathbf{0}, \mathbf{D})$. Generated random parameters were then used to make PS crown-width predictions. Finally, the mean of the 10000 PS predictions was used as the PA prediction for each tree in each plot.

To evaluate the predictive capabilities of all fixed models and their mixed model counterparts, the following statistics were calculated for both datasets based on PA predictions by fixed models and PS, TM and PA predictions by mixed models:

(8) $\quad \overline{\mathrm{e}}=\frac{1}{N} \sum_{i=1}^{N} \mathrm{e}_{i}=\frac{1}{N} \sum_{i=1}^{N}\left(\mathrm{CW}_{i}-\widehat{\mathrm{CW}}_{i}\right)$

(9a) RMSE $=\sqrt{\frac{1}{N-s} \sum_{i=1}^{N}\left(\mathrm{CW}_{i}-\widehat{\mathrm{CW}}_{i}\right)^{2}}$

(9b) $\operatorname{RMSE}_{p}=\sqrt{\frac{1}{N} \sum_{i=1}^{N}\left(\mathrm{CW}_{i}-\widehat{\mathrm{CW}}_{i}\right)^{2}}$

(10) $\delta=\overline{\mathrm{e}}^{2}+\mathrm{SD}^{2}, \mathrm{SD}=\sqrt{\frac{1}{N-1} \sum_{i=1}^{N}\left(\mathrm{e}_{i}-\overline{\mathrm{e}}\right)^{2}}$

Where $\mathrm{CW}_{i}$ and $\widehat{\mathrm{CW}}_{i}$ are the observed and predicted crown widths for tree $i=1,2, \ldots, N$; $N$ the total number of trees in each dataset; $\mathrm{e}_{i}$ the prediction error for tree $i$; $\overline{\mathrm{e}}$ the mean prediction error; $s$ the number of fixed parameters; RMSE and $\mathrm{RMSE}_{p}$ the root mean square errors calculated on model fitting and model validation data, respectively; SD the standard deviation of the prediction errors; and $\delta$ an overall accuracy measure that combines the bias and precision.

\section{Results}

\section{Model development}

Table 3 shows the coefficients of determination and root mean square errors for the four alternative base models evaluated on model fitting data. The exponential model (model 3) had the highest $\mathrm{R}^{2}$ and the lowest RMSE and was selected as the base model for further analyses. Fig. 1 shows the plots of residuals versus DBHs and predicted CWs for this model. There was no obvious trend in residuals.

Table 3. Coefficients of determination $\left(R^{2} s\right)$ and root mean square errors (RMSEs) for the four alternative base models

\begin{tabular}{lll}
\hline Model & $\mathbf{R}^{2}$ & RMSE \\
\hline 1 & 0.2598 & 1.0571 \\
2 & 0.2482 & 1.0653 \\
3 & 0.2623 & 1.0553 \\
4 & 0.1230 & 1.1506 \\
\hline
\end{tabular}


The final expanded models at the three levels were:

(11) $\mathrm{CW}=\beta_{0} \exp \left(\beta_{1} \mathrm{DBH}+\beta_{2} \mathrm{CR}\right)+\varepsilon$

(12) $\mathrm{CW}=\beta_{0} \exp \left(\beta_{1} \mathrm{DBH}+\beta_{2} \mathrm{CR}+\beta_{3} \mathrm{HDR}\right)+\varepsilon$

(13) $\mathrm{CW}=\beta_{0} \exp \left(\beta_{1} \mathrm{DBH}+\beta_{2} \mathrm{CR}+\beta_{3} \mathrm{HDR}+\beta_{4} \mathrm{CI} 1_{-} \mathrm{CON}\right)+\varepsilon$

(14) $\mathrm{CW}=\beta_{0} \exp \left(\beta_{1} \mathrm{DBH}+\beta_{2} \mathrm{CR}+\beta_{3} \mathrm{HDR}+\beta_{4}\right.$ SDI_CON $)+\varepsilon$

Where $\mathrm{CR}$ is crown ratio, HDR is height-diameter ratio, CI1_CON is Hegyi's competition index based on coniferous competitors, SDI_CON is stand density index based on coniferous trees (Tables 1 and 2), and $\beta_{2}-\beta_{4}$ are parameters to be estimated.

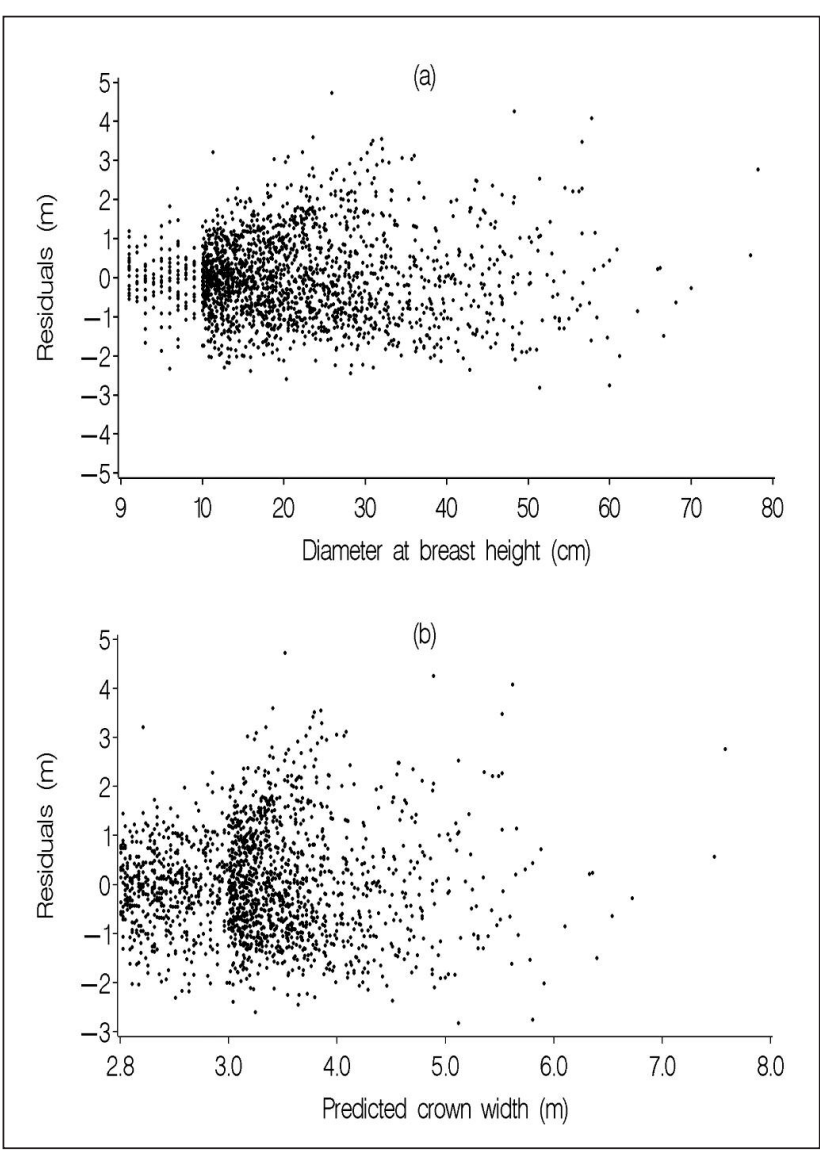

Fig.1. Plots of residuals against $\mathrm{DBH}$ (a) and against predicted crown width (b) for the selected base model (model 3).

Table 4 shows the estimated parameters for the five fixed models $(3,11-14)$ and the associated fit statistics. Compared to model 3, a substantial increase in $\mathrm{R}^{2}$ was observed when crown ratio was included as a predictor in the level 1 expanded model, along with large decreases in RMSE, AIC and BIC. Further increases in $\mathrm{R}^{2}$ and decreases in RMSE, AIC and BIC were achieved by including height-diameter ratio as another predictor in the level 2 model. For the two level 3 models, these fit statistics were further improved, but to a lesser degree. When the two level 3 models were compared, model 13 had an edge over model 14, indicating that the dis- tance-dependent CI1_CON was superior to the distanceindependent SDI_CON for modelling crown width, but only marginally better.

Based on the five fixed models, the best mixed models were:

(15) $\mathrm{CW}_{i j}=\left(\beta_{0}+u_{i 0}\right) \exp \left[\left(\beta_{1}+u_{i 1}\right) \mathrm{DBH}_{i j}\right]+\varepsilon_{i j}$

(16) $\mathrm{CW}_{i j}=\left(\beta_{0}+u_{i 0}\right) \exp \left[\left(\beta_{1}+u_{i 1}\right) \mathrm{DBH}_{i j}+\beta_{2} \mathrm{CR}_{i j}\right]+\varepsilon_{i j}$

(17) $\mathrm{CW}_{i j}=\left(\beta_{0}+u_{i 0}\right) \exp \left[\left(\beta_{1}+u_{i 1}\right) \mathrm{DBH}_{i j}+\beta_{2} \mathrm{CR}_{i j}\right.$

$$
\left.+\beta_{3} \mathrm{HDR}_{i j}\right]+\varepsilon_{i j}
$$

(18) $\mathrm{CW}_{i j}=\left(\beta_{0}+u_{i 0}\right) \exp \left[\left(\beta_{1}+u_{i 1}\right) \mathrm{DBH}_{i j}+\beta_{2} \mathrm{CR}_{i j}\right.$

$$
\left.+\beta_{3} \mathrm{HDR}_{i j}+\beta_{4} \mathrm{CI}_{-} \mathrm{CON}_{i j}\right]+\varepsilon_{i j}
$$

(19) $\mathrm{CW}_{i j}=\left(\beta_{0}+u_{i 0}\right) \exp \left[\left(\beta_{1}+u_{i 1}\right) \mathrm{DBH}_{i j}+\beta_{2} \mathrm{CR}_{i j}\right.$

$$
\left.+\beta_{3} \mathrm{HDR}_{i j}+\beta_{4} \mathrm{SDI}_{-} \mathrm{CON}_{i}\right]+\varepsilon_{i j}
$$

Where $\mathrm{CW}_{i j}, \mathrm{DBH}_{i j}, \mathrm{CR}_{i}, \mathrm{HDR}_{i,}, \mathrm{CI} \mathrm{CON}_{i j}$ and $\varepsilon_{i j}$ are the observed crown width, diameter, crown ratio, height-diameter ratio, Hegyi's index based on coniferous competitors and the error term, respectively, for the $j$ th tree in the $i$ th plot; $i=1,2, \ldots m ; \mathrm{j}=1,2, \ldots n_{i} ; m$ the total number of plots in the population; $n_{i}$ the number of trees in the $i$ th plot; SDI_CON ${ }_{i}$ stand density index based on coniferous trees for the $i$ th plot; and $u_{i 0}$ and $u_{i 1}$ random parameters associated with $\beta_{0}$ and $\beta_{1}$ for the $i$ th plot.

For all fixed models, incorporating two random parameters produced the best fits. For the four expanded models with more than two fixed parameters (models 16-19), the two random parameters were associated with the same parameters $\beta_{0}$ and $\beta_{1}$. Including more than two random parameters either produced failed model convergence or non-significant parameters for some variance and covariance parameters and/or fixed parameters.

Table 4. Parameter estimates (Par) and their standard errors in brackets for the five fixed models as well as associated fit statistics (Stat) of $\mathrm{R}^{2}$, RMSE, AIC and BIC

\begin{tabular}{lccccc}
\hline Par/Stat & Model 3 & Model 11 & Model 12 & Model 13 & Model 14 \\
\hline$\beta_{0}$ & 2.408223 & 1.404304 & 2.620278 & 2.85489 & 3.023889 \\
& $(0.0360)$ & $(0.0342)$ & $(0.1557)$ & $(0.1675)$ & $(0.1800)$ \\
$\beta_{1}$ & 0.014662 & 0.014216 & 0.010332 & 0.00842 & 0.009774 \\
& $(0.0004)$ & $(0.0003)$ & $(0.0005)$ & $(0.0005)$ & $(0.0005)$ \\
$\beta_{2}$ & - & 0.844586 & 0.683127 & 0.624781 & 0.572482 \\
& - & $(0.0306)$ & $(0.0329)$ & $(0.0327)$ & $(0.0342)$ \\
$\beta_{3}$ & - & & & & \\
& - & - & $(0.0483)$ & $(0.0483)$ & $(0.0474)$ \\
$\beta_{4}$ & - & - & - & -0.02165 & -0.0002 \\
& - & - & - & $(0.0024)$ & $(0.0000)$ \\
$\mathrm{R}^{2}$ & 0.2623 & 0.4839 & 0.5168 & 0.5371 & 0.5364 \\
RMSE & 1.0553 & 0.8829 & 0.8545 & 0.8366 & 0.8372 \\
AIC & 5765.4 & 5068.5 & 4941.9 & 4860.0 & 4862.7 \\
BIC & 5782.1 & 5090.8 & 4969.8 & 4893.5 & 4896.2 \\
\hline
\end{tabular}


Table 5. Parameter estimates (Par) and their standard errors in brackets for the five mixed models as well as associated fit statistics (Stat) of AIC and BIC

\section{Par/Stat Model 15 Model 16 Model 17 Model 18 Model 19}

\begin{tabular}{|c|c|c|c|c|c|}
\hline$\beta_{0}$ & $\begin{array}{c}2.3297 \\
(0.0481)\end{array}$ & $\begin{array}{c}1.5635 \\
(0.0470)\end{array}$ & $\begin{array}{c}2.9591 \\
(0.1695)\end{array}$ & $\begin{array}{c}3.2329 \\
(0.1859)\end{array}$ & $\begin{array}{c}3.2419 \\
(0.1952)\end{array}$ \\
\hline$\beta_{1}$ & $\begin{array}{l}0.01715 \\
(0.0006)\end{array}$ & $\begin{array}{l}0.01631 \\
(0.0006)\end{array}$ & $\begin{array}{c}0.01173 \\
(0.0006)\end{array}$ & $\begin{array}{c}0.009743 \\
(0.0007)\end{array}$ & $\begin{array}{l}0.01153 \\
(0.0006)\end{array}$ \\
\hline$\beta_{2}$ & $\begin{array}{l}- \\
-\end{array}$ & $\begin{array}{c}0.6066 \\
(0.0360)\end{array}$ & $\begin{array}{c}0.4780 \\
(0.0358)\end{array}$ & $\begin{array}{c}0.4435 \\
(0.0355)\end{array}$ & $\begin{array}{c}0.4509 \\
(0.0359)\end{array}$ \\
\hline$\beta_{3}$ & $\begin{array}{l}- \\
-\end{array}$ & $\begin{array}{l}- \\
-\end{array}$ & $\begin{array}{l}-0.5783 \\
(0.0458)\end{array}$ & $\begin{array}{c}-0.5141 \\
(0.0461)\end{array}$ & $\begin{array}{c}-0.5596 \\
(0.0455)\end{array}$ \\
\hline$\beta_{4}$ & $\begin{array}{l}- \\
-\end{array}$ & - & - & $\begin{array}{r}-0.01812 \\
(0.0026)\end{array}$ & $\begin{array}{c}-0.00015 \\
(0.0000)\end{array}$ \\
\hline$\sigma_{1}^{2}$ & $\begin{array}{l}0.40050 \\
(0.0555)\end{array}$ & $\begin{array}{l}0.09262 \\
(0.0166)\end{array}$ & $\begin{array}{c}0.2790 \\
(0.0514)\end{array}$ & $\begin{array}{c}0.2854 \\
(0.0583)\end{array}$ & $\begin{array}{c}0.2999 \\
(0.0592)\end{array}$ \\
\hline$\sigma_{12}$ & $\begin{array}{l}-0.00223 \\
(0.0006)\end{array}$ & $\begin{array}{c}-0.00092 \\
(0.0002)\end{array}$ & $\begin{array}{l}-0.00127 \\
(0.0004)\end{array}$ & $\begin{array}{l}-0.00110 \\
(0.0005)\end{array}$ & $\begin{array}{r}-0.00127 \\
(0.0005)\end{array}$ \\
\hline$\sigma_{2}^{2}$ & $\begin{array}{c}0.000039 \\
(0.0000)\end{array}$ & $\begin{array}{c}0.000028 \\
(0.0000)\end{array}$ & $\begin{array}{c}0.000023 \\
(0.0000)\end{array}$ & $\begin{array}{c}0.000021 \\
(0.0000)\end{array}$ & $\begin{array}{c}0.000021 \\
(0.0000)\end{array}$ \\
\hline$\sigma^{2}$ & $\begin{array}{l}0.44730 \\
(0.0167)\end{array}$ & $\begin{array}{c}0.4408 \\
(0.0164)\end{array}$ & $\begin{array}{c}0.4071 \\
(0.0150)\end{array}$ & $\begin{array}{c}0.4003 \\
(0.0147)\end{array}$ & $\begin{array}{c}0.4083 \\
(0.0150)\end{array}$ \\
\hline AIC & 4771.0 & 4551.0 & 4390.3 & 4343.7 & 4373.4 \\
\hline BIC & 4793.6 & 4577.4 & 4420.4 & 4377.6 & 4407.2 \\
\hline
\end{tabular}

$\sigma_{1}^{2}$ and $\sigma_{2}^{2}$ are the variances for random parameters $u_{i 0}$ and $u_{i 1}$, respectively; $\sigma_{12}$ is the covariance between $u_{i 0}$ and $u_{i 1}$; and $\sigma^{2}$ is the residual variance.

Table 5 shows the estimated fixed parameters, variance and covariance parameters for random effects and residual variances for the five mixed models, as well as the associated AIC and BIC statistics. The AIC and BIC statistics became smaller as model complexity increased from model 15 to 19 . However, the reductions were not as large as those from the fixed models, suggesting that a simpler mixed model was capable of providing nearly as good a fit as a more complex mixed model, as long as the most important predictors (DBH and CR in this study) were included. Similar to the two level 3 fixed models, model 18 produced better fit than model 19, indicating that the distance-dependent CI1_CON was superior to the distance-independent SDI_CON for modelling crown width, but only marginally better.

All mixed models provided substantial improvements over their fixed model counterparts. The reduction rates in AIC and BIC were $17.2 \%$ and $20.7 \%$, respectively, from model 3 to model 15. As the fixed models became more complex, the reductions in AIC and BIC became smaller. Nevertheless, the reduction rates were still large for all four expanded mixed models over the corresponding fixed models (10-12\%). These results indicated that mixed models provided much better fits than their fixed model counterparts, even for the most complex models.

\section{Model application and evaluation}

Fig. 2 shows the mean prediction errors, root mean square errors and overall accuracy measures on model fitting data for PA predictions by the five fixed models and PS, TM and PA predictions by the five mixed models. All mean prediction errors were small, except for those for TM and PA predictions by the simplest mixed model, model 15 (Fig. 2a). Fig. 2b revealed that the RMSEs for TM and PA predictions by each mixed model were almost identical, and they were slightly larger than the RMSE for PA predictions by the corresponding fixed model. In addition, large decreases in RMSEs were observed for fixed_PA, mixed_TM and mixed_PA from the base models to level 1 models. Further but smaller decreases in RMSEs were observed for these predictions from level 1 to level 2 models. The reductions in RMSEs were negligible from level 2 to level 3 models.

PS predictions from the mixed models, however, had a different trend. All five mixed models produced similar RMSEs, although there were slight decreases in RMSEs as model complexity increased. Since the RMSEs for fixed_PA predictions decreased with increasing fixed model complexity while the RMSEs for mixed_PS predictions were about the same across all mixed models, the reductions in RMSEs from fixed_PA to mixed_PS predictions between the fixed and mixed model pairs became smaller as model complexity increased. In addition, mixed_PS predictions had much smaller RMSEs than the other three types of predictions (29-43\% lower, Fig. $2 b$ ). Trends similar to RMSEs were observed for the overall accuracy measure d (Fig. 2c).

Fig. 3 shows the mean prediction errors, root mean square errors and overall accuracy measures on model validation data for PA predictions by the fixed models and PS, TM and PA predictions by the mixed models. Several things are obvious.

The mean prediction errors were almost identical between TM and PA predictions by each of the five mixed models (Fig. 3a). They were also larger than the mean prediction errors for PA predictions by the corresponding fixed models. The simplest fixed and mixed models produced large negative mean prediction errors. When CR was included as an additional predictor, the mean prediction errors became much smaller in absolute values, but still large. When one more predictor HDR was incorporated, the absolute values of the mean prediction errors were further reduced. No further reductions were observed when the two CIs were included in the two level 3 models. In fact, the absolute values of the mean prediction errors even increased slightly. The mean prediction errors for PS predictions by the mixed models, on the other hand, were much smaller, and the differences were small among the five models (Fig. 3a).

Similar to model fitting data, the RMSEs were almost identical for mixed_TM and mixed_PA predictions by each mixed model, and they were slightly larger than the RMSE for PA predictions by the corresponding fixed model. In addition, large reductions in RMSEs were observed for fixed_PA, mixed_TM and mixed_PA predictions as model complexity increased from the base models to level 2 models. The RMSEs for mixed_PS predictions, on the other hand, were similar for all mixed models. Therefore, the reductions in RMSEs from fixed_PA to mixed_PS predictions became smaller as model complexity increased. The RMSEs for mixed_PS predictions were also much smaller than the RMSEs for fixed_PA, mixed_TM and mixed_PA predictions (Fig. 3b). 

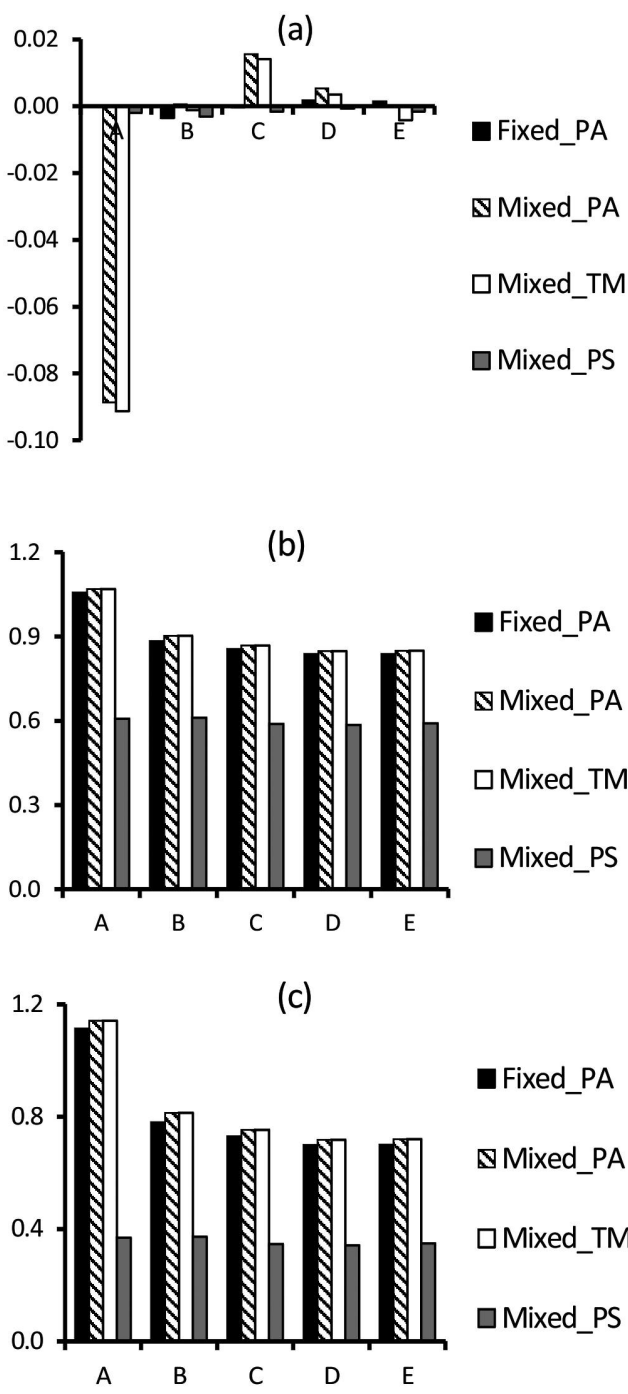

Fig. 2. Mean prediction errors (a), root mean square errors (b) and overall accuracy measures (c) on model fitting data for PA predictions by fixed models and PA, TM and PS predictions by mixed models, where A refers to base models ( $3 \& 15)$, B refers to level 1 models (11\&16), $C$ refers to level 2 models (12\&17), and $\mathrm{D}$ and $\mathrm{E}$ refer to level 3 models (D: $13 \& 18, E$ : 14 \&19).

Trends similar to RMSEs were observed for the overall accuracy measure $\delta$ (Fig. 3c). What was different was that for the simplest models, and to a lesser degree for level 1 models, the differences in $\delta$ were larger between fixed_PA predictions and mixed_TM and mixed_PA predictions. In addition, the $\delta$ values for mixed_PS predictions were even smaller compared to those for fixed_PA, mixed_TM and mixed_PA predictions, from about five fold for the base models to about three fold for the level three models.

When all results were considered, the best fixed and mixed models were the level 2 expanded models 12 and 17.

\section{Discussion}

Fixed and mixed tree crown width models with increasing levels of complexity were developed in this study. Some prior studies (e.g., Gill et al. 2000) found that DBH alone was suffi-

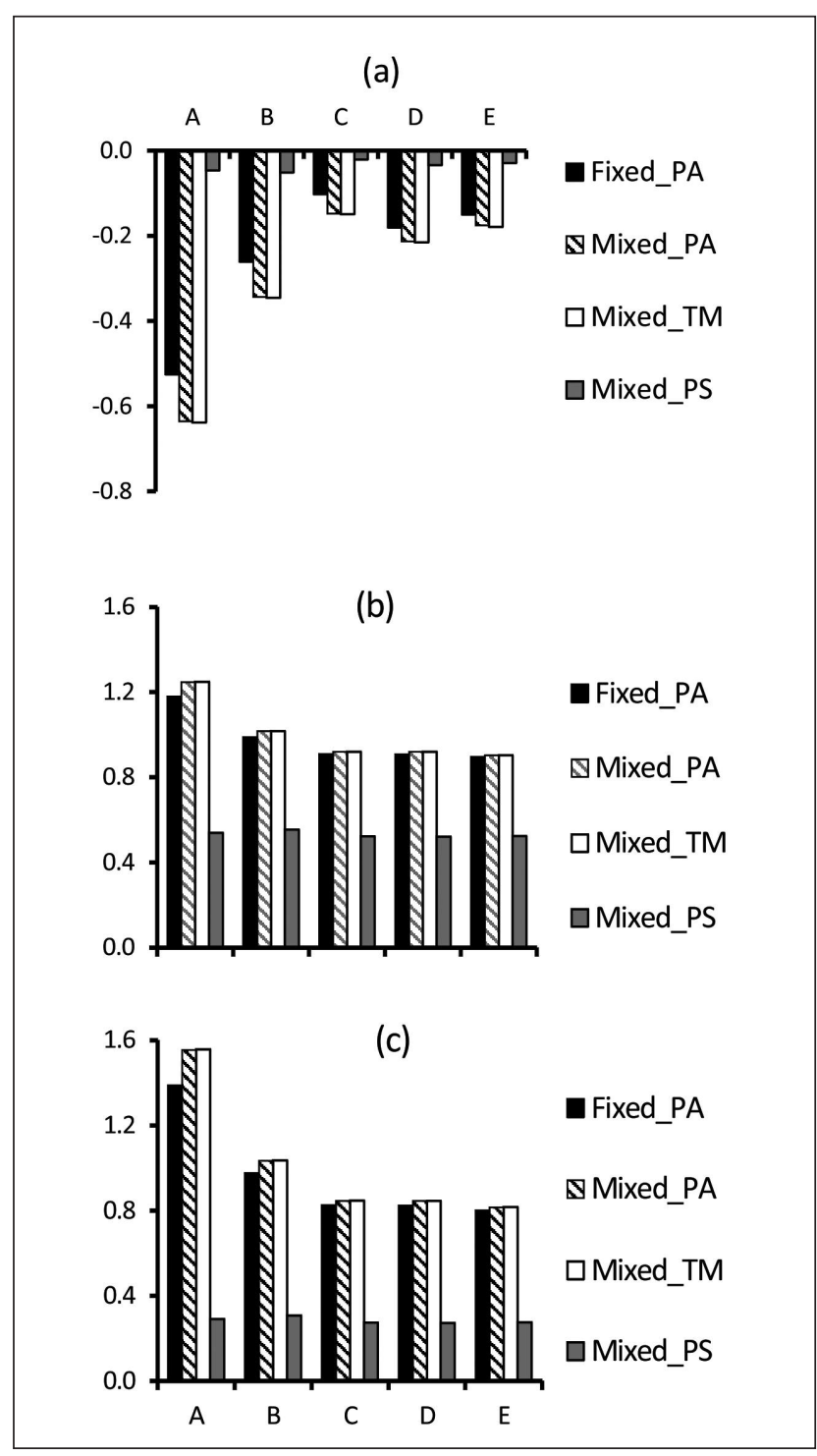

Fig. 3. Mean prediction errors (a), root mean square errors (b) and overall accuracy measures (c) on model validation data for PA predictions by fixed models and PA, TM and PS predictions by mixed models, where A refers to base models ( 3 \&15), B refers to level 1 models (11\&16), C refers to level 2 models (12\&17), and $D$ and $E$ refer to level 3 models (D: $13 \& 18, E$ : 14 \&19).

cient for crown width modelling, while others (e.g., Bragg 2001) found that including other predictors improved crown width predictions. Crown width models using DBH as the only predictor may be sufficiently accurate for stands where the densities are similar, but not for stands with a wide range of stand conditions (Rouvinen and Kuuluvainen 1997, Bragg 2001). Our results favoured this conclusion, because the simplest crown width model with $\mathrm{DBH}$ as the only predictor performed poorly, particularly for the model validation data.

When tree crown ratios and height-diameter ratios were sequentially included as additional predictors, substantial improvements were observed in fit statistics and in crown width predictions. Hann (1998) found that crown ratio was an effective predictor of crown width, but others concluded otherwise (Gill et al. 2000, Bechtold 2003). Mixed results were reported by Russell and Weiskittel (2011) for different species. 
For this study, crown ratio led to the largest marginal improvement when alternative single predictors were considered alone.

In addition, both distance-dependent and distance-independent CIs were evaluated for their effects on crown width modelling and predictions. Among all distance-independent CIs examined, Reineke's stand density index calculated from coniferous trees (SDI_CON) was the best one. del Río et al. (2014) also found that CIs based on the stand density index concept were better than those based on basal area because the latter is more influenced by stand development and environmental conditions. Among all distance-dependent CIs examined, Hegyi's CI calculated from coniferous competitors (CI1_CON) was the best one. Between the two CIs, CI1_CON was slightly better than SDI_CON. Davies and Pommerening (2008) hypothesized and subsequently demonstrated that distance-dependent CIs were superior to distance-independent CIs for crown width modelling and predictions. Our results support that conclusion, but the differences between the two types of CIs are minimal.

When developing an ordinary least squares model, it is key to include the most significant predictors in the model, provided that the model is not over-parameterized. This is often difficult to achieve. Some predictors are unknown or very difficult and/or costly to measure. A key advantage of mixed models is their ability to account for various sources of heterogeneity caused by known and unknown factors as well as the dependence caused by grouped structures (Vonesh and Chinchilli 1997). In addition, they can provide localized model predictions.

When developing a mixed model, an important step is defining the fixed model form before random effects are included. Temesgen et al. (2008) demonstrated that including both random effects and stand-level variables had little effect on RMSEs for tree height predictions compared with just including random effects and tree-level predictors. However, including stand-level variables was helpful when a small number of trees in each stand were subsampled for height. Kershaw et al. (2009) found that although mixed models significantly improved model fit for all levels of model complexity, the amount of improvement declined as the fixed portion of the mixed models became more complex. This is understandable since more data variation is explained by the more complex fixed-effects part. As a result, less variation is explained by the random-effects part, including the error term. This was confirmed by this study. The RMSEs and overall accuracy measures for PA predictions by the fixed models decreased as model complexity increased. However, these two statistics were very similar for mixed_PS predictions across all mixed models, and for both the model fitting and model validation datasets. As a result, the reductions in the two statistics from fixed_PA to mixed_PS predictions became smaller as model complexity increased. Nevertheless, mixed_PS predictions were still substantially better than fixed_PA predictions for all five model pairs.

Mixed models can be used to generate three types of predictions. If crown width measurement is available for at least one tree in a plot, PS predictions can be generated by a mixed model for the remaining trees in the plot. When such information is not available, mixed_TM predictions are often generated by assuming random parameters to be zero. These predictions are often used as substitutes for PA predictions by fixed models (Fang and Bailey 2001). However, it has been pointed out by Meng et al. (2009) and Burkhart and Tome (2012) that mixed_TM predictions were often biased and did not represent PA predictions by fixed models. de-Miguel et al. (2012) and Mehtätalo et al. (2015) proposed a simulation approach to produce Mixed_PA predictions when there is no prior information available on the dependent variable. Instead of predicting random parameters using subject-specific information, they proposed to randomly generate random parameter values based on the estimated variancecovariance matrix of the random effects and then calculate PS predictions. Mixed_PA predictions were simply the averages of these PS predictions over the distribution of random effects. For this study, each of the five mixed models produced comparable mixed_PA and mixed_TM predictions, indicating that the simple mixed_TM predictions can be used as a substitute to the complex mixed_PA predictions when prior information is not available to make mixed_PS predictions.

As the mixed models became more complex from the base model to level 2 model, improved mixed_TM and mixed_PA predictions were achieved. However, only marginal improvements in mixed_TM and mixed_PA predictions were observed from level 2 to level 3 models. On the other hand, all five mixed models produced similar PS predictions. These results suggested that if a mixed crown width model was developed for making TM, PA and PS predictions, the level 2 model should be used. Since the most complex level 3 mixed models did not offer much improvement in model predictions, their use was not recommended. This is important, especially for model 18 where the calculation of CI1_CON requires tree locations, which are often not available in forest growth and yield data. If a mixed crown width model was developed for making PS predictions only, the simplest model 15 was good enough to provide accurate crown width predictions, and the more complicated models did not provide extra benefits.

\section{Conclusions}

Two types of crown width models, fixed and mixed, were developed for white spruce in Alberta. For each type, five models with increasing levels of complexity were fitted. The base model used $\mathrm{DBH}$ as the only predictor, while the four expanded models included additional predictors. Based on model fitting and model validation results, we concluded the following: (1) the mixed models were superior to their fixed model counterparts in fit statistics and for making PS predictions, but the fixed models provided better PA predictions than mixed_PA and mixed_TM predictions by the mixed models; (2) increasing model complexity by incorporating more predictors generally improved fit statistics for both fixed and mixed models, and produced more accurate fixed_PA, mixed_TM and mixed_PA predictions; and (3) the distancedependent CI1_CON was marginally superior to the distance-independent SDI_CON for crown width modelling, but both CIs did not provide substantial improvements, especially for model predictions. Since the ultimate goal of developing these models was to make crown width predictions, the level 2 models with DBH, CR and HDR as predictors (models 12 and 17) were recommended as the final fixed and mixed models. These models should be more transportable given more fixed-effects predictors. 


\section{Acknowledgements}

This research was supported by the Alberta Government. The constructive comments and suggestions from Mr. Darren Aitkin, an anonymous reviewer and the Associate Editor are appreciated.

\section{References}

ASRD. 2005. Permanent sample plot (PSP) field procedures manual. Forest Management Branch, Alberta Sustainable Resource Development, Edmonton, Alberta.

Bechtold, W.A. 2003. Crown-diameter prediction models for 87 species of stand-grown trees in the eastern United States. South. J. Appl. For. 27(4): 269-278.

Biging, G.S. and M. Dobbertin. 1995. Evaluation of competition indices in individual tree growth models. For. Sci. 41: 360-377.

Bragg, D.C. 2001. A local basal area adjustment for crown width prediction. North. J. Appl. For. 18(1): 22-28.

Burkhart, H.E. and M. Tomé. 2012. Modeling Forest Trees and Stands. Springer, Dordrecht.

Condés, S. and H. Sterba. 2005. Derivation of compatible crown width equations for some important tree species of Spain. For. Ecol. Manage. 217: 203-218.

Crecente-Campo, F., P. Marshall, V. LeMay and U. DiéguezAranda. 2009. A crown profile model for Pinus radiata D. Don in northwestern Spain. For. Ecol. Manage. 257: 2370-2379.

Crookston, N.L. and G.E. Dixon. 2005. The Forest Vegetation Simulator: a review of its applications, structure, and content. Comp. Electr. Agric. 49: 60-80.

Das, A., J. Battles, P.J. van Mantgem and N.L. Stephenson. 2008. Spatial elements of mortality risk in old-growth forests. Ecology 89(6: 1744-1756.

Davies, O. and A. Pommerening. 2008. The contribution of structural indices to the modelling of Sitka spruce (Picea sitchensis) and birch (Betula spp.) crowns. For. Ecol. Manage. 256: 68-77.

Davidian, M. and D.M. Giltinan. 2003. Nonlinear models for repeated measurement data: an overview and update. J. Agric. Biol. Environ. Stat. 8: 387-419.

de-Miguel, S., L. Mehtätalo, Z. Shater, B. Kraid and T. Pukkala. 2012. Evaluating marginal and conditional predictions of taper models in the absence of calibration data. Can. J. For. Res. 42 (7): 1383-1394.

del Río, M., S. Condés and H. Pretzsch. 2014. Analyzing size-symmetric vs. size-asymmetric and intra- vs. inter-specific competition in beech (Fagus sylvatica L.) mixed stands. For. Ecol. Manage. 325: 90-98.

Fang, Z. and R.L. Bailey. 2001. Nonlinear mixed effects modeling for slash pine dominant height growth following intensive silvicultural treatments. For. Sci. 47: 287-300.

Fitzmaurice, G.M., N.M. Laird and J.H. Ware. 2004. Applied longitudinal analysis. John Wiley \& Sons, New York.

Fu, L., H. Sun, R.P. Sharma, Y. Lei, H. Zhang and S. Tang. 2013. Nonlinear mixed-effects crown width models for individual trees of Chinese fir (Cunninghamia lanceolata) in south-central China. For. Ecol. Manage. 302: 210-220.

Gill, S.J., G.S. Biging and E.C. Murphy. 2000. Modeling conifer tree crown radius and estimating canopy cover. For. Ecol. Manage. 126: 405-416.

Hann, D.W. 1998. Equations for predicting the largest crown width of stand-grown trees in western Oregon. Forest Research Laboratory, Oregon State University, Corvallis. Research Contribution 17.

Hays, R.L, C. Summers and W. Seitz. 1981. Estimating wildlife habitat variables. USDI Fish and Wildlife Serv., FWS/OBS-81/47.

Hegyi, F. 1974. A simulation model for managing jack-pine stands. In Growth models for tree and stand simulation (J. Fries, ed.). Royal College of Forestry, Stockholm, pp. 74-90.
Hemery, G.E., P.S. Savill and S.N. Pryor. 2005. Applications of the crown diameter-stem diameter relationship for different species of broadleaved trees. For. Ecol. Manage. 215: 285-294.

Jiménez-Pérez, J., O.A. Aguirre-Calderón and H. Kramer. 2006. Tree crown structure in a mixed coniferous forest in México. In: Conference on International Agricultural Research for Development. University of Bonn, Oct. 11-13, 2006, pp. 649-654.

Kershaw, J.A., J.G. Benjamin Jr and A.R. Weiskittel. 2009. Approaches for modeling vertical distribution of maximum knot size in black spruce: a comparison of fixed- and mixed-effects nonlinear models. For. Sci. 55: 230-237.

Ledermann, T. and A.R. Stage. 2001. Effects of competitor spacing in individual-tree indices of competition. Can. J. For. Res. 31: 2143-2150.

Littell, R.C., G.A. Milliken, W.W. Stroup, R.D. Wolfinger and O. Schabenberger. 2006. SAS for mixed models. $2^{\text {nd }}$ ed., SAS Institute Inc.

Lorimer, C.G. 1983. Tests of age-independent competition indices for individual trees in natural hardwood stands. For. Ecol. Manage. 6: 343-360.

McCulloch, C.E. and S.R. Searle. 2001. Generalized, Linear, and Mixed Models. John Wiley \& Sons.

Meng, S.X., S. Huang, Y. Yang, G. Trincado and C.L. VanderSchaaf. 2009. Evaluation of population-averaged and subject-specific approaches for modeling the dominant or codominant height of lodgepole pine trees. Can. J. For. Res. 39: 1148-1158.

Meng, S.X., S. Huang, C.L. VanderSchaaf, Y. Yang and G. Trincado. 2012. Accounting for serial correlation and its impact on forecasting ability of a fixed and mixed-effects basal area model: a case study. Eur. J. For. Res. 131: 541-552.

Mehtätalo, L., S. de-Miguel and T.G. Gregorie. 2015. Modeling height-diameter curves for prediction. Can. J. For. Res. 45: 826-837. Paulo, M.J., A. Stein and M. Tomé. 2002. A spatial statistical analysis of cork oak competition in two Portuguese silvopastoral systems. Can. J. For. Res. 32: 1893-1903.

Pinheiro, J.C. and D.M. Bates. 2004. Mixed-effects models in S and S-PLUS. Springer, New York.

Pretzsch, H. and J. Dieler. 2012. Evidence of variant intra- and interspecific scaling of tree crown structure and relevance for allometric theory. Oecologia 169: 637-649.

Reineke, L.H. 1933. Perfecting a stand-density index for even-aged forests. J. Agric. Res. 46: 627-638.

Rouvinen, S. and T. Kuuluvainen. 1997. Structure and asymmetry of tree crowns in relation to local competition in a natural mature Scots pine forest. Can. J. For. Res. 27: 890-902.

Russell, M.B. and A.R. Weiskittel. 2011. Maximum and largest crown width equations for 15 tree species in Maine. North. J. Appl. For. 28: 84-91.

Sánchez-González, M., I. Cañellas and G. Montero. 2007. Generalized height-diameter and crown diameter prediction models for cork oak forests in Spain. Investigación Agraria: Sistemas y Recursos Forestales 16: 76-88.

Temesgen, H., V.J. Monleon and D.W. Hann. 2008. Analysis and comparison of nonlinear tree height prediction strategies for Douglas-fir forests. Can. J. For. Res. 38: 553-565.

Thorpe, H.C., R. Astrup, A. Trowbridge and K.D. Coates. 2010. Competition and tree crowns: a neighborhood analysis of three boreal tree species. For. Ecol. Manage. 259: 1586-1596.

Yang, Y. and S. Huang. 2011. Estimating a multilevel dominant height-age model from nested data with generalized errors. For. Sci. 57: 102-116.

Vonesh, E.F. and V.M. Chinchilli. 1997. Linear and nonlinear models for the analysis of repeated measurements. Marcel Dekker.

Zarnoch, S.J., W.A. Bechtold and K.W. Stolte. 2004. Crown condition as an indicator of forest health. Can. J. For. Res. 34: 1057-1070. 